NBER WORKING PAPER SERIES

\title{
PARETO IMPROVING SOCIAL SECURITY REFORM WHEN FINANCIAL MARKETS ARE INCOMPLETE!?
}

\author{
Dirk Krueger \\ Felix Kubler \\ Working Paper 9410 \\ http://www.nber.org/papers/w9410
}
NATIONAL BUREAU OF ECONOMIC RESEARCH
1050 Massachusetts Avenue
Cambridge, MA 02138
December 2002

We thank Piero Gottardi, John Heaton, Karsten Jeske, Ken Judd, Narayana Kocherlakota, Laurence Kotliko, Victor Rios-Rull, Kent Smetters, Jorge Soares, Nick Souleles and seminar participants at the 2002 AEA Winter Meetings, the 2001 ET Conference, the 2001 SCE Conference, the Tow Conference in Iowa, the Wharton Macro Lunch, SITE, the Atlanta FED, the Intergenerational Risk Sharing and Contracts Conference in Fiesole, USC, Stanford and the Minnesota FED for helpful suggestions. We gratefully acknowledge support from NSF grant SES-0004376. All remaining errors are our own. The views expressed herein are those of the authors and not necessarily those of the National Bureau of Economic Research.

(C) 2002 by Dirk Krueger and Felix Kubler. All rights reserved. Short sections of text not to exceed two paragraphs, may be quoted without explicit permission provided that full credit including, (C) notice, is given to the source. 
Pareto Improving Social Security Reform when Financial Markets are Incomplete!?

Dirk Krueger and Felix Kubler

NBER Working Paper No. 9410

December 2002

JEL No. H55, D91, H31, E62, D58

\section{$\underline{\text { ABSTRACT }}$}

This paper studies an Overlapping Generations model with stochastic production and incomplete markets to assess whether the introduction of an unfunded social security system can lead to a Pareto improvement. When returns to capital and wages are imperfectly correlated, the consumption variance of all generations can be reduced if government policies enable them to pool labor and capital incomes. A social security system that endows retired households with a claim to labor income may serve as an effective tool to share aggregate risk between generations. Our quantitative analysis shows that, first, abstracting from the crowding-out effect of social security on the aggregate stock in general equilibrium, the introduction of social security does indeed represent a Pareto improving reform, if households are both fairly risk-averse and fairly willing to intertemporally substitute consumption. Second, the severity of the capital crowding-out effect in general equilibrium overturns these gains for degrees of risk aversion and intertemporal elasticity of substitution commonly used in the literature.

Dirk Krueger

Department of Economics

Stanford University

Stanford, CA 94305

and NBER

dkrueger@leland.stanford.edu
Felix Kubler

Department of Economics

Stanford University

Stanford, CA 94305 


\section{Introduction}

The current US pay-as-you go social security system was introduced in 1935, partly as a response to the impoverishment of an entire generation during the great depression, the biggest negative aggregate shock the US economy has experienced so far. In the current political debate about social security reform one of the major concerns cited by the opponents of a reform towards a funded system is the risk of low returns to savings for an entire generation due to a large and unfavorable aggregate shock (see Aaron et al. (2001) or Burtless (2001) for a discussion).

The role that an unfunded social security system may play in facilitating the allocation of aggregate risk among generations is also a key discussion point in the current academic debate. Shiller (1999) and Bohn (1998, 1999) have argued that, if returns to capital and wages are imperfectly correlated and subject to aggregate shocks, then the consumption variance of all generations can be reduced if private markets or government policies enable them to pool their labor and capital incomes. A social security system that endows retired households with a claim to labor income may serve as such an effective tool to share aggregate risk between generations, in the absence of financial securities that achieve the same risk allocation.

The idea that market failures might give a normative justification for a pay-as-you-go public retirement plan dates back at least to Diamond (1977). He points out that the absence of certain investment opportunities may lead to inefficient risk allocations. Merton (1983) analyzes the economic inefficiencies caused by the non-tradeability of human capital in an overlapping generations model with stochastic production. He suggests that the present social security system may help to eliminate these inefficiencies.

It is the goal of this paper to evaluate the quantitative importance of this intergenerational risk sharing role of social security, in comparison to the more traditional arguments of reducing overaccumulation of capital and intragenerational insurance and redistribution. We ask whether, in a situation like in 1935, after a large adverse macroeconomic shock, it is possible to justify the introduction of an unfunded, redistributive pay-as-you go social security system on the normative grounds that it provides a welfare improvement for all generations then alive and for generations to be born into all future states of the world (an ex interim Pareto improvement).

Our economy is populated by nine overlapping generations that face stochastic, imperfectly correlated wages and returns to capital, stemming from a standard neoclassical production function that is hit by produc- 
tivity and depreciation shocks. Households have a preference for smooth consumption, both over time and across states and can transfer resources across time by purchasing claims to the risky aggregate capital stock. By assuming a recursive utility representation as in Kreps and Porteus (1978) and Epstein and Zin (1989) we can control risk aversion independently from the willingness to intertemporally substitute consumption. The government administers a pure pay-as-you-go defined contribution social security system by collecting a payroll tax at constant rate $\tau$ and paying out benefits that vary with stochastic aggregate wages, in order to insure budget balance of the system. With the introduction of such a system, since wages and returns to capital are imperfectly correlated, the government in effect forces households to hold a second asset and thus to diversify capital income risk. This risk diversification element is the only positive role social security plays in our economy. In particular we provide a sufficient theoretical condition for the equilibrium without social security to be dynamically efficient and assure that in all our quantitative analysis this condition is satisfied. Therefore social security is not beneficial because it cures overaccumulation of capital or leads to better allocation of (average) resources across generations, but solely because it enhances risk sharing between generations. This beneficial role of social security has to be traded off against its lower average implicit return, compared with other assets, and the crowding-out of physical capital that its introduction induces.

Our quantitative analysis exhibits two main findings. First, abstracting from the crowding-out effect of social security on the aggregate stock in general equilibrium the introduction of social security does indeed represent a Pareto improving reform, if (and only if) households are fairly risk-averse and fairly willing to intertemporally substitute consumption. This result is obtained even though the return differential between private returns to capital and implicit returns to the social security system amounts to 4.9 percentage points, indicating a strong positive effect of social security on the intergenerational allocation of risk. Second, the severity of the capital crowding-out effect in general equilibrium overturns these gains for degrees of risk aversion and intertemporal elasticity of substitution commonly used in the macroeconomic and public finance literature. However, even in general equilibrium the introduction of social security is a Pareto-improving reform if households are highly risk averse and, in addition, have a very high intertemporal elasticity of substitution or if the excess return of private assets over social security is significantly lower than observed in the data. 
The paper is organized as follows. In the next section we develop a simple, analytically tractable model that aims at formalizing the intuition outlined above and at providing a back-of-the-envelope calculation of the welfare consequences of social security reform. Section 3 describes the general equilibrium model, relates our paper to the existing theoretical literature and contains the sufficient condition for dynamic efficiency of equilibrium. Section 4 discusses the calibration of the model and Section 5 summarizes our main results, first for a partial equilibrium and then for a general equilibrium version of the model. Conclusions are contained in Section 6, and the appendix offers further details about our theoretical derivations as well as on the data used in the paper.

\section{A Simple Model}

\subsection{Theory}

In this section we present a simple, two period partial equilibrium model to formalize the intuition discussed in the introduction. Each agent lives for two periods, earns wage $w_{0}$ in the first period on which she pays a payroll $\operatorname{tax} \tau$. The remainder of her wages is invested into a risky savings technology with stochastic gross return $R$. In the second period of her life she receives social security payments of $\tau w_{0} G$, where $G$ is the stochastic gross return of the social security system. The agent values consumption in the second period of her live, with consumption given by

$$
c=(1-\tau) w_{0} R+\tau w_{0} G
$$

according to the differentiable utility function $v(c)$. Lifetime utility, as a function of the size of the social security system, is therefore given by

$$
U(\tau)=E v\left[(1-\tau) w_{0} R+\tau w_{0} G\right]
$$

where $E($.$) is the first period conditional expectation with respect to uncer-$ tainty realized in the second period of the households' life.

We ask under what condition a marginal introduction of a social security system is welfare-improving, that is, we seek necessary and sufficient conditions under which

$$
U^{\prime}(\tau=0)>0
$$

Under the assumption that $v(c)=\ln (c)$ and that $G$ and $R$ are jointly lognormal (3) reduces to (after some tedious algebraic manipulations presented 
in the appendix)

$$
E\left\{\frac{G}{R}\right\}=\frac{E(G)}{E(R)} \cdot \frac{\left[c v(R)^{2}+1\right]}{\left[\rho_{G, R} \cdot c v(G) \cdot c v(R)+1\right]}>1
$$

where $\rho_{G, R}=\frac{\operatorname{Cov}(G, R)}{\operatorname{Std}(G) \operatorname{Std}(R)}$ is the correlation coefficient between $G$ and $R$ and $c v(R)=\frac{E(R)}{S t d(R)}$ is the coefficient of variation of the risky savings returns, with $c v(G)$ defined accordingly.

From (4) we see that the introduction of a marginal social security system is welfare improving if the implicit expected return to social security, $E(G)$ is sufficiently large relative to the return on the risky saving technology, $E(R)$. Even if the latter is substantially larger than the former, the introduction of social security may still be justified if the stochastic saving returns are sufficiently volatile (i.e. $c v(R)$ sufficiently big) and/or the correlation between private saving returns and returns to social security sufficiently small (or negative). We will calibrate our general equilibrium model exactly to these statistics from the data which this simple model has pointed to as crucial in determining the welfare consequences of social security.

For general utility function of the CRRA form $v(c)=\frac{c^{1-\sigma}-1}{1-\sigma}$ and without any distributional assumptions on $(G, R)$ condition (4) can be generalized to

$$
E\left(\frac{G-R}{R^{\sigma}}\right)=E\left(\frac{G}{R^{\sigma}}\right)-E\left(R^{1-\sigma}\right)>0
$$

With appropriate data on private returns to saving $R$ and implicit returns to the social security system $G$ equation (5) can be used to provide a first quantitative assessment whether the introduction of a (small) social security system can be justified on the grounds of a better risk allocation, abstracting from all intertemporal consumption and general equilibrium effects. It may also provide an estimate of the degree of risk aversion required for this argument to work.

\subsection{Empirical Implementation}

We empirically map the gross returns $R$ into returns to the S\&P 500, as documented by Shiller (1989), and the gross return to social security $G$ into the gross growth rate of real total compensation of employees from NIPA, as provided by the Bureau of Economic Analysis (BEA). For details please consult the data appendix. 


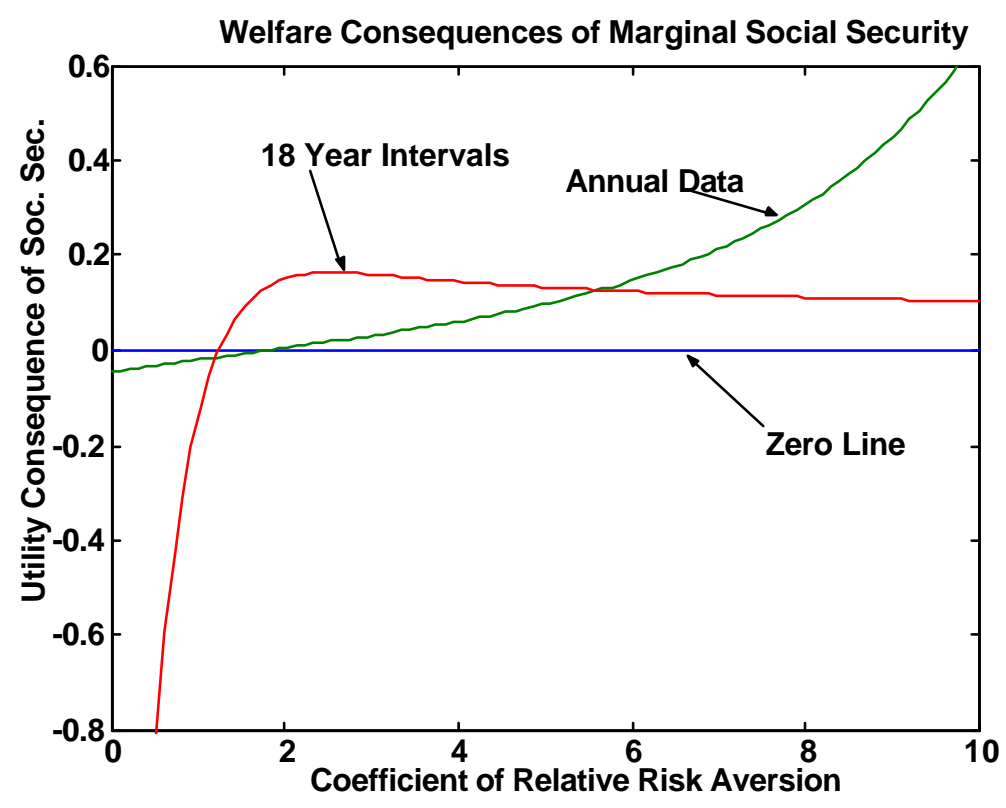

Figure 1: Welfare Consequences of Social Security Reform

A key question is what time interval in the data corresponds to a model period. Our data is available in yearly frequency; since in our simple model agents live for two periods, a model period may more reasonably be interpreted as twenty years. We present results for alternative data frequencies, for annual data, and for data of 18-year frequency.

In Figure 1 we plot, using the data for $R$ and $G$ condition (5) against the degree of risk aversion $\sigma$. We see that for degrees of risk aversion of 2 and higher the introduction of a marginal social security system is beneficial, when the judgement is based on the criterion (5) from our simple two-period partial equilibrium model.

The question of whether the better risk allocation induced by the (marginal) introduction of social security is welfare improving then becomes a quantitative one. To at least partially answer it requires to construct a computable dynamic general equilibrium model, calibrated to data, a task which we turn next to. 


\section{The General Model}

Our model is a straightforward extension of Diamond's (1965) economy to aggregate uncertainty.

\subsection{Time and Uncertainty}

Time is discrete and extends from $t=0, \ldots, \infty$. Aggregate uncertainty is represented by an event tree. The root of the tree is given by some fixed event $z_{0}$. Each node of the tree is a history of exogenous shocks to the economy $z^{t}=\left(z_{0}, z_{1} \ldots z_{t}\right)$. Let by $\pi_{t}\left(z^{t}\right)$ denote the probability that the node $z^{t}$ occurs. We let the notation $z^{t} \succ z^{s}$ mean that $z^{s}$ is a potential successor node of $z^{s}$, for $t>s$.

The shocks are assumed to follow a Markov chain with finite support $\mathcal{Z}$ and (in slight abuse of notation) with transition matrix $\pi$. There are three commodities at each node, labor, a single consumption good and a capital good which can only be used as an input to production.

\subsection{Demographics, Endowments and Preferences}

The economy is populated by overlapping generations of agents that live for nine periods. ${ }^{1}$ The population growth rate is given by $n$. In each period $t$, $L_{t}=(1+n) L_{t-1}$ identical new households are born. By $L_{0}=1$ let denote the number of newborns in period 0 . A household is fully characterized by the node in which she is born $\left(z^{t}\right)$. When there is no ambiguity about the identity of households we will index them simply by their date of birth.

An agent born at node $z^{s}$ has non-negative, deterministic labor endowment over her life-cycle, $\left(l^{0}, l^{1}, \ldots, l^{8}\right)$. The price of the consumption good at each date event is normalized to one and at each date event $z^{t}$ the household supplies her labor endowment inelastically for a market wage $w\left(z^{t}\right)$.

Let by $c^{s}\left(z^{t}\right)$ denote the consumption of an agent born at time $s$ in period $t \geq s$ and by $U^{s}\left(c, z^{t}\right)$ the expected continuation utility of an agent born in node $z^{s}$ from node $z^{t} \succ z^{s}$ onwards. An agent born at node $z^{s}$ therefore has expected lifetime utility from allocation $c$ given by $U^{s}\left(c, z^{s}\right)$. Individuals have preferences over consumption streams representable by the following recursive utility representation (see Kreps and Porteus (1978) and

\footnotetext{
${ }^{1}$ The lifespan of nine periods constitutes a compromise between realism and the need to keep the number of state variables relatively small for our compational strategy to remain feasible.
} 
Epstein and Zin (1989))

$$
U^{s}\left(c, z^{t}\right)=\left\{\left[c^{s}\left(z^{t}\right)\right]^{\rho}+\beta\left[\sum_{z_{t+1}} \pi\left(z_{t+1} \mid z_{t}\right)\left(U^{s}\left(c, z^{t+1}\right)\right)^{\sigma}\right]^{\frac{\rho}{\sigma}}\right\}^{\frac{1}{\rho}}
$$

where $\frac{1}{1-\rho}$ is the intertemporal elasticity of substitution and $1-\sigma$ measures the risk aversion of the consumer with respect to atemporal wealth gambles. We assume $\sigma<1$ and $\rho<1, \rho \neq 0$. Note that if $\rho=\sigma$, then households have standard constant relative risk aversion expected utility, with CRRA of $1-\sigma$, if the final continuation utility function is given by $U^{s}\left(c, z^{s+8}\right)=c^{s}\left(z^{s+8}\right)$, which we shall assume. ${ }^{2}$

Households have access to a storage technology: they can use one unit of the consumption good to obtain one unit of the capital good next period. We denote the investment of household $s$ into this technology by $a^{s}\left(z^{t}\right)$. All agents are born with zero assets, $a^{s}\left(z^{s-1}\right)=0$. We do not restrict $a^{s}\left(z^{t}\right) \geq$ 0 , because we want to permit households to borrow against future labor income. At time $t$ the household sells its capital goods accumulated from last period, $a^{s}\left(z^{t-1}\right)$, to the firm for a market price $1+r\left(z^{t}\right)>0$. The budget constraint of household $s$ in period $t \geq s$ therefore reads as

$$
c^{s}\left(z^{t}\right)+a^{s}\left(z^{t}\right)=\left(1+r\left(z^{t}\right)\right) a^{s}\left(z^{t-1}\right)+(1-\tau) l^{t-s}\left(z_{t}\right) w\left(z^{t}\right)+I(s) b\left(z^{t}\right)
$$

where $\tau$ is the payroll tax to finance social security payments, $b\left(z^{t}\right)$ are the social security benefits received by a retired agent and $I(s)$ is the indicator function, with $I(s)=1$ for $s \geq a g e_{\text {ret }}$ and $I(s)=0$ otherwise. ${ }^{3}$ Here age ret is the retirement age.

${ }^{2}$ For the isoelastic utility case $\rho=0$ preferences are represented recursively by

$$
U^{s}\left(c, z^{t}\right)=\left[c^{s}\left(z^{t}\right)\left(\sum_{z_{t+1}} \Pi\left(z_{t+1} \mid z_{t}\right) U^{s}\left(c, z^{t+1}\right)^{\sigma}\right)^{\frac{\sum_{j=1}^{s+8-t} \beta^{j}}{\sigma}}\right]^{\frac{1}{\sum_{j=0}^{s+8-t} \beta^{j}}}
$$

It can be shown that the limit of the Euler equations for (6), as $\rho \rightarrow 0$, converge to the Euler equations for (7)

${ }^{3}$ Note that benefits $b\left(z^{t}\right)$ only depend on the aggregate event history, but not on individual income, whereas in the actual U.S. systems benefits do depend on individual labor earnings, although in a fairly progressive fashion. There is also a maximum income level beyond which no further social security contributions are levied. Even though our modeling choice may attribute too much intergenerational risk sharing to the social security 
To start off the economy we assume that at the root node, i.e. in period zero, there are $L_{0} /(1+n)^{i}$ households of ages $i=0, \ldots, 8$ who enter the period with given capital holdings $a_{-1}^{0}, \ldots, a_{-1}^{-8}$, where by assumption $a_{-1}^{0}=$ 0

\subsection{Firms}

There is a single representative firm which in each period $t$ uses labor and capital to produce the consumption good according to a constant returns to scale production function $f_{t}\left(K, L ; z_{t}\right)$. Since firms make their decisions on how much capital to buy and how much labor to hire after the realization of the shock $z_{t}$ they face no uncertainty and simply maximize current period profits. $^{4}$

In our quantitative work below we will always use the following parametric form for the production function.

$$
f_{t}(K, L)=\xi\left(z_{t}\right) K^{\alpha}\left[(1+g)^{t} L\right]^{1-\alpha}+K\left(1-\delta\left(z_{t}\right)\right)
$$

where $\eta($.$) is the stochastic shock to productivity, where \delta(.) \in[0,1]$ can be interpreted as the (possibly) stochastic depreciation rate.

\subsection{Government}

The only role the government has in our model is to levy payroll taxes to pay for social security benefits. We model social security as a defined contribution pay-as-you-go system that adheres to period by period budget balance, with size characterized by the payroll tax rate $\tau$. This requires that taxes and benefits satisfy

$$
\tau w\left(z^{t}\right) L\left(z^{t}\right)=b\left(z^{t}\right) L_{t}^{r e t}
$$

where $L\left(z^{t}\right)$ is total labor input at node $z^{t}$ and $L_{t}^{r e t}=L_{0} \sum_{s=a g e_{r e t}}^{8}(1+n)^{t-s}$ is the total number of retired people in the economy.

system by failing to account for the linkage between benefits and contributions, given the progressive nature of the system it provides a reasonable first approximation, without average lifetime income becoming an additional state variable for each generation.

${ }^{4}$ We assume that households cannot convert capital goods back into consumption goods at the beginning of the period. This assumption is necessary to prevent households from consuming the capital at the beginning of the period instead of selling it to the firm in states where the net return to capital is negative. 


\subsection{Markets}

In this simple economy the only markets are spot markets for consumption, labor and capital, all of which are assumed to be perfectly competitive.

\subsection{Equilibrium and Pareto Efficiency}

As discussed in the introduction we will study equilibria for two versions of our model. The first is a standard closed general equilibrium economy, in which all capital used in domestic production is owned by domestic agents. In the second economy part of the productive capital stock may be owned by the rest of the world; we assume that in this economy the total supply of capital for the production process is exogenously fixed at $\bar{K}_{t}$, part of which is owned by domestic agents and part of which is owned by the rest of the world. $\bar{K}_{t}=[(1+n)(1+g)]^{t} \bar{K}$ grows at rate $n+g$ per period. We refer to this version of the model either as partial equilibrium or small open economy.

For given initial conditions $z_{0},\left(a_{-1}^{s}\right)_{s=-8}^{0}$ a competitive equilibrium for the closed economy is a collection of choices for households $\left(c^{s}\left(z^{t}\right), a^{s}\left(z^{t}\right)\right)_{t=s}^{s+8}$, for the representative firm $\left\{K\left(z^{t}\right), L\left(z^{t}\right)\right\}$, a policy $\left\{\tau, b\left(z^{t}\right)\right\}$ as well as prices $\left\{r\left(z^{t}\right), w\left(z^{t}\right)\right\}$ such that a) given prices and policies households and the firm maximize, b) the government budget constraint (10) is satisfied and c) markets clear: for all $t, z^{t}$

$$
\begin{aligned}
L\left(z^{t}\right) & =(1+n)^{t} \sum_{s=0}^{8} \frac{l^{s}}{(1+n)^{s}} \\
K\left(z^{t}\right) & =(1+n)^{t} \sum_{s=1}^{8} \frac{a^{t-s}\left(z^{t-1}\right)}{(1+n)^{s}} \\
(1+n)^{t} \sum_{s=0}^{8} \frac{c^{t-s}\left(z^{t}\right)}{(1+n)^{s}}+K\left(z^{t-1}\right) & =f_{t}\left(K\left(z^{t}\right), L\left(z^{t}\right), z_{t}\right)
\end{aligned}
$$

By Walras' law market clearing in the labor and capital market imply market clearing in the consumption goods market for the closed economy. For the small open economy the labor market clearing condition (11) remains the same, the capital market clearing condition now reads as

$$
K\left(z^{t}\right)=\bar{K}_{t}
$$

and the goods market clearing condition is not any longer part of the equilibrium definition. ${ }^{5}$

\footnotetext{
${ }^{5}$ Foreign investors claim a fraction $\left(\bar{K}_{t}-K_{d o m}\left(z^{t}\right)\right) F_{K}$ of output as capital income,
} 
Finally, an allocation $(c, K)$ is (ex interim) Pareto efficient if it is feasible and there is no other feasible allocation $(\hat{c}, \hat{K})$ such that $U^{s}\left(\hat{c}, z^{s}\right) \geq U^{s}\left(c, z^{s}\right)$ for all $z^{s}$ and $U^{s}\left(\hat{c}, z^{s}\right)>U^{s}\left(c, z^{s}\right)$ for at least one $z^{s}$.

In order to solve for the equilibrium numerically using recursive techniques we de-trend the economy by deterministic population growth and technological progress. Denoting growth adjusted consumption by $\tilde{c}$, and other variables accordingly ${ }^{6}$, the Euler equations from the individuals' optimization problem, the recursive version of which our numerical algorithm will operate on, read as

$$
\left[E_{z^{t}}\left(\tilde{U}_{t+1}^{s}\right)^{\sigma}\right]^{\frac{\rho}{\sigma}-1} \tilde{\beta} E_{z^{t}}\left[\frac{\tilde{c}^{s}\left(z^{t+1}\right)}{\tilde{c}^{s}\left(z^{t}\right)}\right]^{\rho-1}\left(\frac{1+r\left(z^{t+1}\right)}{1+g}\right)\left(\tilde{U}_{t+1}^{s}\right)^{\sigma-\rho}=1 .
$$

Since each agents' optimization problem is finite-dimensional and convex, these Euler equations are necessary and sufficient for optimal household choices.

In order to compute equilibrium allocations numerically we formulate these Euler equations recursively. We then define and compute a Functional Rational Expectations Equilibrium (FREE), following the approach pioneered by Spear (1988) and adapted to stochastic OLG models by Krueger and Kubler (2002). ${ }^{7}$

\subsection{The Thought Experiment}

In this paper we are interested in the following thought experiment: Suppose that in an equilibrium of the economy for a payroll tax rate $\tau=0$ at some date-event $z^{t}$, there is an unanticipated increase of $\tau$. What are the welfare effects for all individuals born at $z^{t}$ and at all successor nodes?

Evidently, in order to determine whether an introduction of a social security system (i.e. an increase of $\tau$ to a positive value) improves welfare for all future generations, one needs to compare welfare at infinitely many

with the rest of output being available for investment into the domestically owned capital stock $K_{\text {dom }}\left(z^{t}\right)$ and domestic consumption.

${ }^{6}$ More precisely, define $\tilde{c}^{s}\left(z^{t}\right)=\frac{c^{s}\left(z^{t}\right)}{[1+g]^{t}}, \tilde{\beta}=(1+g)^{\rho} \beta$ and $\tilde{U}_{t}^{s}=\frac{U^{s}\left(c, z^{t}\right)}{(1+g)^{t}}$.

${ }^{7} \mathrm{~A}$ FREE is a recursive competititive equilibrium where the policy functions are restricted to smooth functions, defined on a compact state space, and with range in a compact set, so that the Markov process induced by the exogenous shocks and the policy functions never leaves the compact set that constitutes the state space, once it is started in that set. The bounds of the state space are part of the definition of a FREE. See Krueger and Kubler (2002) for the details. 
nodes. In our quantitative work below, we report welfare gains and losses for the next 2-3 periods (corresponding to about 20 years in real time) and verify that the qualitative conclusions remain the same over 4-10 periods. It turns out that in our examples we do not have to consider more periods to make conclusive welfare statements, since the welfare consequences of the reform stabilize after at most 4 periods.

\subsection{Dynamic Efficiency and Pareto Efficiency}

Since financial markets are incomplete, it is well known that in our setup equilibrium allocations are generally suboptimal and that a social planner could find Pareto-improving transfers. When discussing possible risk-sharing benefits of a pay-as-you-go social security system we focus on a particular intervention. We do not argue that a social security system guarantees full efficiency and we do not attempt to explain why this particular system is in place. We simply want to examine if it is Pareto-improving to introduce social security.

Whereas our paper focuses on inefficiencies caused by sequentially incomplete financial markets, since Samuelson (1958) and Diamond (1965) it is well known that overlapping generation models can exhibit Pareto suboptimal equilibria for completely different reasons. Even in deterministic exchange economies, transfers from young to old agents, which do not constitute a new asset with different risk characteristics can be Pareto-improving (dynamic inefficiency). In economies with production a reduction in capital accumulation can lead to Pareto improvement through higher aggregate consumption at all future dates (production inefficiency).

Demange (2002) generalizes the notion of dynamic efficiency to economies with uncertainty and possibly incomplete asset markets. An allocation is called dynamically efficient, if there exists no other allocation in the marketed subspace which constitutes a Pareto improvement. An argument similar to Samuelson (1958) can be used to demonstrate that equilibria in our economies may be dynamically inefficient.

However, in our analysis we focus on inefficient risk sharing across generations (due to incomplete markets), rather than on dynamic or production inefficiencies as a source of market failures. When returns on available assets are sufficiently high, equilibrium allocations are production efficient and dynamically efficient. When, in addition, markets are sequentially complete the equilibrium is Pareto efficient and social security can never be Paretoimproving. In other words, if assets yield high enough returns, the ineffi- 
ciency of risk sharing studied in this paper is the only inefficiency that may provide a rationale for public transfer programs.

Are returns on assets are sufficiently high? Abel et al. (1989) argue empirically that the US economy is dynamically efficient. ${ }^{8}$ In addition there is an important theoretical argument for focusing on dynamically efficient economies. An asset that promises to pay a non-negligible fraction of aggregate consumption at each future state of the world (e.g. land, see Demange (2002)) can only have a finite price today if the allocation is dynamically efficient. Therefore equilibria in models with such assets are necessarily dynamically efficient.

However, the conclusion that dynamic efficiency implies Pareto efficiency depends crucially on the assumption that markets are sequentially complete. If markets are incomplete allocations will generally not be Pareto-efficient, even if returns of traded assets are high and thus equilibrium allocations are dynamically efficient. In this paper we therefore want to assess whether in a realistically calibrated economy that is, judging from rates of return on capital, dynamically efficient, the introduction of a social security system is Pareto-improving. For this we need to provide a sufficient and numerically implementable condition on returns to capital that guarantees dynamic efficiency. Our analysis extends Demange's (2002) argument to homothetic economies with population and productivity growth.

For each value of the shock $z$, define a production function in intensive units $\kappa=\frac{K}{L}$ by

$$
\phi(\kappa ; z)=\xi(z) F(\kappa, 1)-(1+\delta(z)) \kappa
$$

Define a supporting price system $\left(q\left(z^{t}\right)\right)$ by $q\left(z_{0}\right)=1$ and

$$
E\left(q\left(z^{t}\right) \frac{\partial \phi\left(\kappa\left(z^{t}\right), z\right)}{\partial \kappa} \mid z^{t-1}\right)=q\left(z^{t-1}\right)(1+n)(1+g)
$$

Since markets are not sequentially complete, there are several supporting price systems, which we collect in a set $\mathcal{Q}$. The following proposition (Theorem 1 in Demange (2002)) characterizes dynamically efficient allocations.

Proposition 1 An equilibrium allocation is dynamically efficient if

$$
\lim _{t \rightarrow \infty} \inf _{q \in \mathcal{Q}} E_{0}\left(\sum_{s=t}^{t+8} q\left(z^{s}\right)\right)=0
$$

\footnotetext{
${ }^{8}$ But see Barbie et al. (2001), for an alternative view on this point.
} 
The proposition states that it is sufficient for optimality that the infimum over all supporting prices tends to zero. Therefore we can verify dynamic efficiency if we find some supporting price system that satisfies Condition (18).

This condition can obviously not be easily verified since it involves prices 'at infinity'. Since we focus on equilibria with a compact state space $\mathcal{S}$, we can give a more useful sufficient condition. For a given time horizon $T$ define the $T$-period expected discounted present value by

$$
R(T)=E_{z_{0}}\left[\Pi_{s=1}^{T} \frac{(1+n)(1+g)}{1+r\left(z^{s}\right)}\right] .
$$

Denote by $\Theta \in \mathcal{S}$ the vector of endogenous state variables (i.e. the aggregate capital stock and the asset holdings of each generation). We have the following

Proposition 2 A Functional Rational Expectations Equilibrium (FREE) is dynamically efficient if there exists a $T>0$ such that for all initial conditions $(z, \Theta) \in \mathcal{Z} \times \mathcal{S}$ in the compact state space the resulting equilibrium returns satisfy $R(T)<1$.

Proof: By definition of a FREE all $z_{T}, \Theta\left(z^{T}\right)$ will lie in $\mathcal{Z} \times \mathcal{S}$ themselves and can be viewed as initial conditions as well. Therefore it follows that $R(i T) \rightarrow 0$ as $i \rightarrow \infty$ Defining

$$
\tilde{q}\left(z^{t+1}\right)=\frac{(1+n)(1+g) \tilde{q}\left(z^{t}\right)}{1+r\left(z^{t+1}\right)}
$$

implies the sufficient condition (18). QED

In the applications below it suffices to consider $T=1$. With Jensen's inequality for $T=1$, our result implies that the allocation is dynamically efficient if the conditional expected returns to capital lies above $(1+g)(1+$ $n$ ) for all possible states in the state space. Also note that from Zilcha (1990) it follows that, independently of the market structure, allocations are production efficient if (18) holds true.

\section{Calibration}

In order to quantify the welfare effects of introducing an unfunded social security system we first have to parameterize our model. This amounts to 
specifying the aggregate stochastic process governing total factor productivity and stochastic depreciation, population growth and the life-cycle labor income profile, average economic growth, the capital share in the production function and parameters governing preferences.

\subsection{Aggregate Growth and Technology}

In our model economy agents life for 9 periods. Therefore we interpret one model period to last 6 years. As population growth rate we choose $n=1.1 \%$ per annum, equal to the average population growth rate for the US postwar period. Similarly we choose the average growth rate of wages equal to $g=1.7 \%$, the long-run average for the US. The labor share in the Cobb-Douglas production function is taken to be $\alpha=0.3$.

We assume that aggregate uncertainty is driven by a four-state Markov chain with state space $Z=\left\{z_{1}, z_{2}, z_{3}, z_{4}\right\}$ and transition matrix $\pi=\left(\pi_{i j}\right)$. Since we want to model both shocks to total factor productivity and to depreciation, a particular state $z_{i}$ maps into a combination of low or high TFP and low or high depreciation.

$$
\begin{aligned}
& T(z)=\left\{\begin{array}{l}
1.0+\nu \text { for } z \in\left\{z_{1}, z_{2}\right\} \\
1.0-\nu \text { for } z \in\left\{z_{3}, z_{4}\right\}
\end{array}\right. \\
& \delta(z)=\left\{\begin{array}{l}
\bar{\delta}-\psi \text { for } z \in\left\{z_{1}, z_{3}\right\} \\
\bar{\delta}+\psi \text { for } z \in\left\{z_{2}, z_{4}\right\}
\end{array}\right.
\end{aligned}
$$

We set $\bar{\delta}$, the average depreciation rate, to 0.31 , reflecting an average depreciation rate of $6 \%$ per year.

The aggregate state $z_{1}$ is characterized by a good TFP-shock and a good depreciation shock (low depreciation), whereas $z_{4}$ features a bad TFP shock and a bad depreciation shock. We assume that the Markov process is a mixture between an iid process and the identity matrix, that is

$$
\pi=(1-w) \Pi+w I
$$

where $I$ is the identity matrix, $w$ is a parameter governing the persistence of the process and $\Pi$ is composed of columns of the form $\left(\Pi_{1}, \Pi_{2}, \Pi_{3}, \Pi_{4}\right)$, where $\Pi_{j}$ is the probability of state $z_{j}$ in the stationary distribution of $\pi$. We assume symmetry in that $\Pi_{1}=\Pi_{4}$ and $\Pi_{2}=\Pi_{3}$. Given the restriction $\sum_{j} \Pi_{j}=1$ the matrix $\pi$ is then uniquely determined by two numbers $\left(\Pi_{1}, w\right)$, which, together with $(\nu, \psi)$ and possibly $\bar{K}$ completely characterize the production technology. 


\subsection{Labor Endowments}

Labor endowments are deterministic and follow the life cycle pattern documented in Hansen (1993). They are documented in Table 1

\section{Table 1: Labor Endowments}

\begin{tabular}{r|rrrrrrrrr} 
age $j$ & 1 & 2 & 3 & 4 & 5 & 6 & 7 & 8 & 9 \\
\hline$l^{j}$ & 1 & 1.35 & 1.54 & 1.65 & 1.67 & 1.66 & 1.61 & 0 & 0
\end{tabular}

This profile implies that, absent aggregate shocks, individual labor earnings have a hump-shaped profile, with peak around the age of 48; at that age individuals earn $67 \%$ more than at their entry into the labor force in their early 20's. Households of age 63 retire and possibly receive social security benefits.

\subsection{Social Security}

We consider various sizes of the social security system, with a benchmark of $\tau=0$ (no social security) and our experiment consisting of the "marginal" introduction of a social security system of size $\tau=2 \%$.

\subsection{Preference Parameters}

Our recursive preferences are uniquely characterized by the intertemporal elasticity of substitution $\frac{1}{1-\rho}$, the time discount factor $\beta$ and the risk aversion parameter $1-\sigma$. Since our results depend crucially on these parameters we report outcomes for different combinations of these parameters.

\subsection{Calibration Targets and Benchmark Parameterization}

We first present results for the small open economy in which the capital crowding-out effect of social security is absent by construction. The technology parameters $\left(\Pi_{1}, w, \nu, \psi, \bar{K}\right)$ are chosen jointly so that the benchmark model competitive equilibrium delivers the following statistics from aggregate data on wages and returns to capital, which we interpret as the S\&P 500. Note again that our model period lasts for 6 years, and thus the statistics reported below refer to wage and return data over six year periods. ${ }^{9}$

1. An average real return on risky capital of $7.7 \%$ per annum

\footnotetext{
${ }^{9}$ For details on the source of the data used as well as the construction of the statistics, see the appendix.
} 
2. A coefficient of variation of average wages of 0.133

3. A correlation coefficient between wages and returns to risky capital of 0.418

4. A coefficient of variation for the return of capital of 0.808

5. A serial correlation of wages of 0.623

Loosely speaking, the parameter $\bar{K}$ determines the average return on capital, the shock to TFP, $\nu$, determines the variability of wages, conditional on $\nu$ the shock to depreciation $\psi$ determines the variability of returns to capital, the probability $\Pi_{1}$ determines how correlated returns to capital and labor are and finally $w$ controls the autocorrelation of wages. Note that in the small open economy, model-generated statistics for wages and returns are independent of the preference parameters and thus need not be re-calibrated as we perform sensitivity analysis with respect to these parameters. This is not be true for the closed economy version of the model. For that model capital accumulation is endogenous, and therefore the parameter $\bar{K}$ is absent from that model. Consequently we choose one of the preference parameters, namely the time discount factor $\beta$, so that the closed economy with $\left(\Pi_{1}, w, \nu, \psi, \beta\right)$ delivers equilibrium observations consistent with the facts above. In anticipation of this we choose as time discount factor for the small open economy $\beta=0.85$, or a time discount rate of $2.7 \%$ per year.

The parameters required for model-generated statistics to coincide with the five empirical observations stated above are $\left(\Pi_{1}, w, \nu, \psi, \bar{K}\right)=(0.294$, $0.623,0.133,0.42,2.18)$. We make the following observations. The probability $\Pi_{1}=\Pi_{4}=0.294>0.25$ is required to match the significantly positive correlation of returns to labor and capital for 6 year time periods in the data. In order for the model to reproduce this observations it has to be sufficiently unlikely that TFP-shocks and depreciation shocks of opposite direction occur simultaneously. The relative magnitude of TFP-shocks and depreciation shocks is explained by the fact that returns to capital are much more volatile in the data than are wages. Since TFP-shocks affect both returns as well as wages directly, the size of these shocks have to be somewhat moderate for wages not to be too volatile. Given this, depreciation shocks have to be of large magnitude to generate returns to capital that are sufficiently volatile in the model.

The required parameter values do not seem to be implausible, with the possible exception of the high variance of the depreciation shock. In particular, the size of $\psi=0.42$ implies that the depreciation rate can be bigger than 
$100 \%$, which makes a literal interpretation of these shocks as depreciation shocks problematic. Table 2 summarizes the benchmark parameterization

\section{Table 2: Benchmark Parameterization}

\begin{tabular}{l|llllllllll} 
Par. & $n(p a)$ & $g(p a)$ & $\alpha$ & $\Pi_{1}$ & $\nu$ & $\psi$ & $\bar{\delta}$ & $w$ & $\beta(p a)$ & $\tau$ \\
\hline Val. & $1.1 \%$ & $1.7 \%$ & 0.3 & 0.29 & 0.13 & 0.42 & 0.31 & 0.62 & 0.97 & 0
\end{tabular}

\section{Results}

\subsection{Small Open Economy with Time-Separable Preferences}

We first investigate whether the basic results from our simple model in section 2 carry over to a model with nontrivial intertemporal choices carried out by households in the model. In Figure 1 we plot the welfare consequences of introducing a marginal unfunded social security system $\tau=2 \%$ against the risk aversion of an agent with standard time separable preferences. Note that increasing the agents' risk aversion is automatically associated with reducing her intertemporal elasticity of substitution, since with standard preferences both attitudes towards risk and attitudes towards intertemporal substitutability of consumption are controlled by the same parameter.

Since the aggregate capital stock is fixed and wages and returns to capital therefore only vary with the exogenous shock $z$, the welfare consequences from such a reform for any newborn agent depend only on the current shock. ${ }^{10}$ We measure welfare changes in consumption equivalent variation (or "consumption", for short): we ask what percentage of extra consumption, in each state, an agent would require in the old equilibrium to be as well of as with the introduction of social security. Positive numbers thus indicate welfare gains from an introduction of social security for a newborn agent, negative numbers indicate welfare losses. To better interpret these numbers, note that without aggregate uncertainty a social security reform simply leads to a reduction in the present discounted value of lifetime income worth $1.9 \%$ of consumption.

We see that the introduction of social security leads to uniform welfare losses for newborn agents, independent of the state at which it is introduced and the risk aversion of the agent. In fact, as risk aversion increases, these losses become more severe, after reaching a minimum at a CRRA of around

\footnotetext{
${ }^{10}$ If aggregate shocks were $i i d$, then the welfare consequences would only depend on the current labor productivity shock and would be the same for shocks $z_{1}, z_{2}$ and $z_{3}, z_{4}$, respectively.
} 
5. The magnitude of the losses center around $1 \%$ of consumption, significantly less than the $1.9 \%$ without uncertainty. Social security does have a beneficial role in reducing the variability of retirement consumption: the coefficient of variation of consumption of agents in their last two periods of life (their retirement) declines by 2 to 5 percentage points (depending on the risk aversion), due to the introduction of social security. However, this effect is insufficient quantitatively to overcome the loss in average lifetime consumption due to the lower returns of social security, compared to private physical capital.

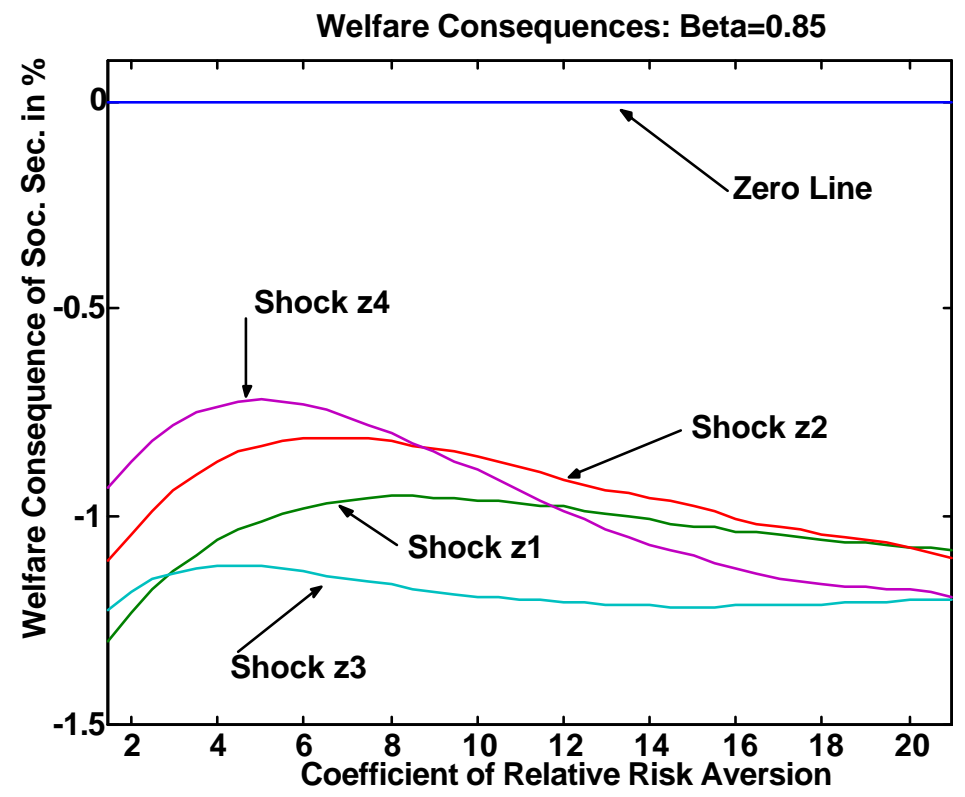

Figure 2: Welfare Consequenses of Social Security Reform

The reason for why increasing risk aversion does not, as in the simple model of Section 2, lead to welfare gains from better risk allocation via social security, lies in the fact that now households make consumption decisions over time. Increasing risk aversion implies a reduction in a households willingness to intertemporally substitute. In an atemporal model this does not matter, but in the current model it crucially determines our results. In particular, in our model with increasing labor income over the life cycle and long run wage growth due to technological progress households borrow at 
high and risky interest rates when young, and more so with social security which taxes labor income in return for retirement income. A reduction in the intertemporal elasticity of substitution makes the desired consumption profile flatter, leads to more borrowing when young and thus reduces the attractiveness of a program that reduces labor income early in life, all other things equal. What drives the results in Figure 2 are therefore not primarily risk considerations, but rather the changes in the IES implied by the changes in attitudes towards risk. ${ }^{11}$

In order to disentangle these effects it is therefore, for the purpose of this paper, crucial to allow for a utility specification in which the degree of risk aversion and the willingness to intertemporally substitute consumption can be controlled independently. Recursive utility permits exactly this, with minimal deviations from standard von Neumann-Morgenstern utility.

\subsection{Small Open Economy with Recursive Preferences}

We now repeat our thought experiment of introducing social security for varying degrees of risk aversion, holding the intertemporal elasticity of substitution $\frac{1}{1-\rho}$ constant. There is substantial disagreement about the size of the IES (see Gouvenen (2002) for an excellent survey of the literature). Estimates from aggregate consumption data tend to be low, around the order of $0-0.2$, whereas studies that use micro data tend to obtain higher values of around 0.2-0.8 (see, e.g. Attanasio and Weber, 1993, 1995). On the other hand the macroeconomic studies cited in Gouvenen (2002), trying to reconcile observations about interest rates and consumption growth rates, argue for an ever higher IES, which leads him to conclude that "(f)or many macroeconomists economic reasoning constitute a strong, albeit indirect, evidence that the IES is quite high, probably close to unity" (p. 7).

We follow the macroeconomic literature and use a unit elasticity of substitution (the log-case) as our benchmark, but also report results for a lower IES of 0.5 , more in line with microeconometric evidence.

From Figure 3 we see that now, holding the intertemporal elasticity of substitution constant, the welfare consequences from introducing social security are monotonically increasing in the agents' risk aversion. In particular, such an introduction is a Pareto-improving reform as long as coefficient of

\footnotetext{
${ }^{11}$ The welfare consequences of introducing social security improve if one increases the discount factor $\beta$, but qualitatively exhibit the same properties as the results summarized in Figure 2.
} 


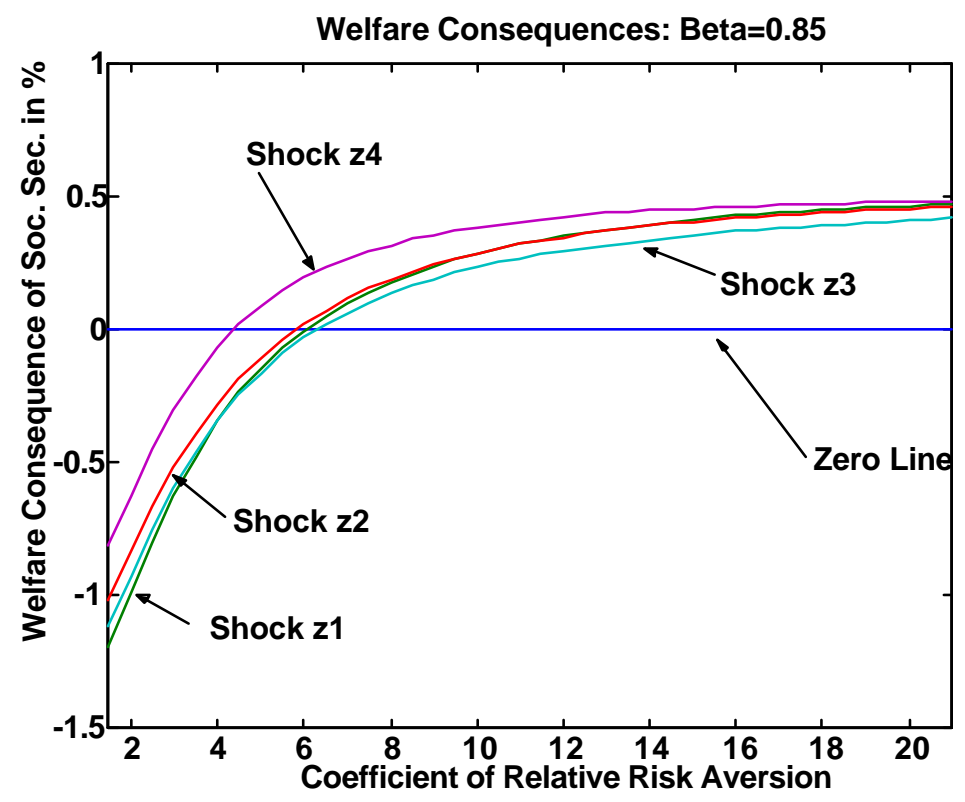

Figure 3: Welfare Consequences of Soc. Sec. Reform: $I E S=1$

relative risk aversion exceeds the value of 5.5, since newborns in all aggregate states of the world are better off with than without social security. ${ }^{12}$

This conclusion, as in the last subsection, depends crucially on the size of the intertemporal elasticity of substitution. Figure 4 confirms our previous results that reducing the IES renders the introduction of social security less beneficial. Now such a reform does not constitute a Pareto improvement since agents born into state $z_{3}$ (with low wages and high returns on capital) lose, even for high degree of risk aversion.

We conclude from this section that introducing an unfunded social security system may constitute a Pareto improving reform, if agents are sufficiently (but not unreasonably) risk averse and willing to substitute consumption over time. However, if capital accumulation is endogenous, such social security reform will reduce private saving and hence reduce the aggregate capital stock and wages. This adverse effect was, by construction, absent in the previous analysis, but is present in the closed economy version

\footnotetext{
${ }^{12}$ Not surprisingly, agents already alive at the date of the reform unambigously gain.
} 


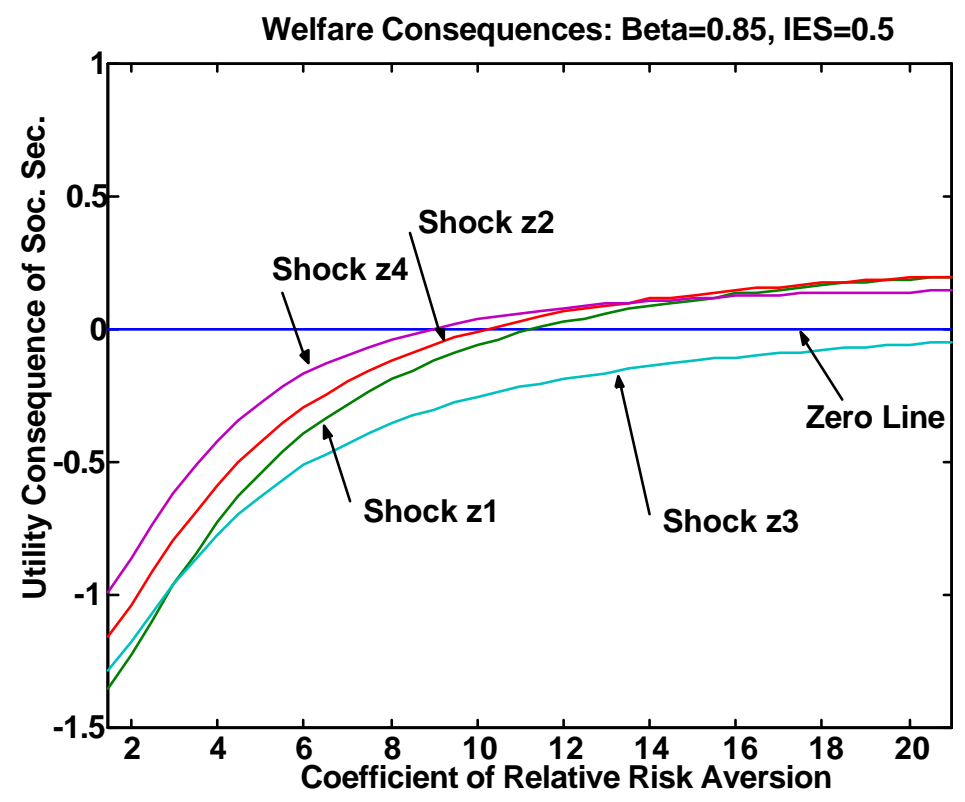

Figure 4: Welfare Consequences of Soc. Sec. Reform: $I E S=0.5$

of our model, the quantitative analysis of which we turn next to.

\subsection{The Crowding-Out Effect of Social Security}

In this section we will only consider parameterizations for the IES which are considered empirically reasonable and for which the small open economy indicates a significant increase in all generations' welfare if risk aversion is sufficiently high. This selection is not meant to imply that we view other parameterizations as empirically unreasonable, but simply reflects the fact that for such parameterizations no additional analysis is needed to arrive at definitive welfare conclusions - the capital crowding out effect of social security can only make matters worse for the reform.

For the IES we maintain a value of unity for the rest of this section. As a benchmark we assume a risk aversion parameter of 15 . This value, which lies outside the range of values commonly deemed reasonable by macroeconomists, but is not uncommon in the finance literature and has some em- 
pirical support from experiments, ${ }^{13}$ produces a solid Pareto improvement from the introduction of social security in the small open economy. We recalibrate the technology parameters, together with the time discount factor $\beta$ so that the equilibrium of the closed economy reproduces the empirical wage and return data summarized in the calibration section. ${ }^{14}$ The required $\beta$ equals 0.85 , as in the small open economy version of the model.

The introduction of social security, in contrast to the small open economy, now changes aggregate production and interest rates. The average return to capital (in the log run, after the transition has been completed) increases from $7.7 \%$ to $7.9 \%$ per annum, the average aggregate capital stock declines by $2.6 \%$, output by $1 \%$ and consumption by $0.4 \%$.

The crowding-out effect, which sets in immediately after the reform has profound consequences for the welfare properties of the reform, summarized in Figure 5. The number attached to a given node of the event tree represents, in consumption equivalent variation, the welfare gains/losses induced by the reform for an agent born at the particular node of the tree. ${ }^{15}$

Whereas generations already alive still benefit from the reform, households born at or after the reform date now lose, in contrast to the case in which the capital-crowding out effect was ignored. Welfare losses increase slightly over time, are fairly uniform across states and amount to about $1 \%$ of consumption. This result is obtained even though, as in the partial equilibrium case, social security does reduce the consumption variance of retired agents significantly (the coefficient of variation of retiree consumption declines by about 2 percentage points).

Increasing the risk aversion further does not qualitatively change the result. For example, with a risk aversion parameter of 30 (and re-calibrating all other parameters so that model statistics are consistent with the data), the welfare losses decline to about $0.8 \%$ for generations 2 periods after the reform (as compared to $1 \%$ in the benchmark parameterization). It is important to note that the welfare gains from intergenerational risk sharing are bounded (see also Figure 2): any intergenerational transfer program of

\footnotetext{
${ }^{13}$ See the summary of the experimental literature by Gollier (2001), and for representative papers in the finance literature, see Kandel and Stambaugh (1991) and Cecchetti et al. (1993).

${ }^{14}$ Since capital accumulation is now endogenous, $\bar{K}$ is no longer a parameter; its role in the calibration is taken by the time discount factor $\beta$.

${ }^{15}$ The aggregate capital stock (and its distribution) at the date at which the reform occurs lies in the middle of the ergodic distribution of the state for the economy without social security. Qualitatively similar results are obtained if other initial conditions are used.
} 


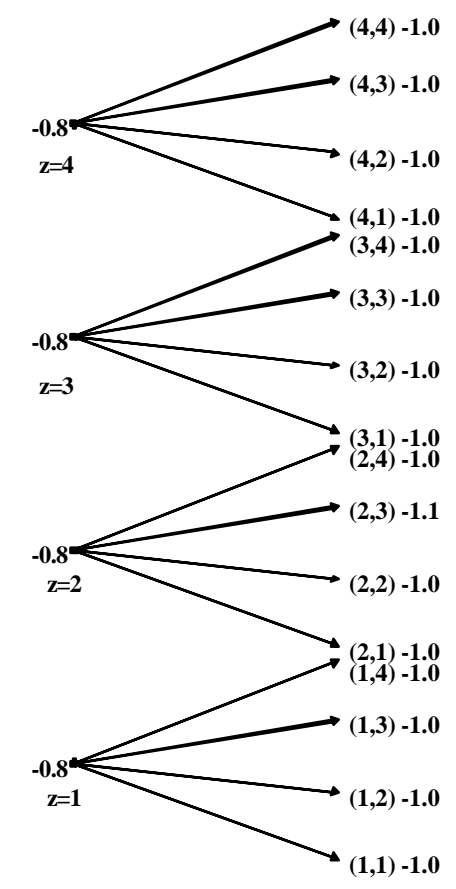

Figure 5: Welfare Cons. with Crowding-Out

the type considered in this paper at best can eliminate consumption risk in retirement completely. The ratio of consumption in the best and in the worst state provides an upper bound on the (consumption equivalent) welfare gains, independent of the risk aversion. If the loss from the return dominance of private capital over social security exceeds this upper bound, even with extremely high risk aversion a social security reform does not generate welfare gains.

We conclude that even for high risk aversion the crowding-out effect of social security dominates the intergenerational risk sharing effect, and therefore the reform does not provide a Pareto improvement.

\subsection{Social Security and Stock Market Returns}

The data on returns of the stock market we use in our calibration section stem from the years 1929-2001. A pay-as-you go social security system was 
in place in the US since the late 1930's. It is therefore possible that high stock market returns in the sample period are partially due to the presence of social security. This possibility is important for our calibration exercise. The main reason why social security has such adverse welfare consequences in general equilibrium is the return differential between risky capital and an unfunded social security system, before its introduction, of roughly $4.9 \%$.

Suppose we take the other extreme view and calibrate our economy in such a way that with an unfunded social security system our model economy reproduces the empirical targets set forth in the calibration section. Qualitatively, since now returns on the risky capital stock in the absence of social security are lower and hence closer to the potential implicit returns of an unfunded social security system, we would expect the welfare consequences of a social security reform to be more favorable. In this section we want to pose and answer two questions a) does such calibration render the economy without social security dynamically inefficient and b) does a (marginal) reform now provide a Pareto improvement.

In particular, we calibrate to the same observations as in the calibration section and use as social security tax rate the current payroll tax rate of $\tau=12.4 \%$. While this is an extreme assumption (for most of the sample period the tax rate was considerably lower), it provides us with the most stringent robustness check of our previous results.

Now a high aversion of agents is sufficient to obtain a Pareto improving social security reform. For a risk aversion parameter of 30 all current and all future generations gain from the introduction of an unfunded social security system with payroll tax rate of $\tau=2 \%$. The welfare gains amount to about $0.2 \%$ for agents born directly at the date of the reform and $0.1 \%$ for agents born farther into the future. The crucial driving force for this result, beyond high risk aversion and fairly high IES of 1 (which alone are not sufficient as argued above) is the reduction of the return differential between capital and social security. Before the introduction of the system the average return to capital now is $6.4 \%$ instead of $7.7 \%$ as under our previous calibration strategy. The economy is still deep inside the dynamically efficient region, as it passes condition (18) easily.

Even though the crowding-out effect is non-negligible for this parametrization (the average capital stock falls by $3.2 \%$, aggregate output by $1 \%$ and aggregate consumption by $0.4 \%$, similar to the benchmark calibration), now its welfare implications are dominated by the benefits of better risk allocation. but its size dominated by better risk allocation. Note that with more moderate degrees of risk aversion (such as a risk aversion parameter of 15 or 
below) the reform does not constitute a Pareto improvement, although now the generation born at the time of the reform gains (as opposed to Figure $5)$.

To us, this example shows that there do exist defendable parameterizations even of the closed economy version of the model for which the introduction of a small unfunded social security system provides a Pareto improvement. Given that the average return on the stock market has a sizeable standard error, calibrating to a return of $6.4 \%$ is not a priori unreasonable. Reducing the target return further, to about $5 \%$ generates a Pareto improvement of the reform even for lower degrees of risk aversion than 15 and still leaves the economy dynamically efficient.

\subsection{The Role of the Intertemporal Elasticity of Substitution}

It is easy to obtain a Pareto improving reform if one resorts to higher (and thus empirically implausible) values for the intertemporal elasticity of substitution, because a higher IES reduces the magnitude of the crowding-out effect of social security. With our calibrated life cycle profile of labor earnings (and the equilibrium relation between time discount factor and interest rate) young agents in the model borrow. As the intertemporal elasticity of substitution (IES) increases (and thus agents value a flat consumption profile less), the incentive to borrow more to offset a payroll tax at young age is declines. The weaker the motive of the young to do additional borrowing, the milder is the required increase in interest rates (and consequent fall in the capital stock) to bring about equilibrium in the capital market after the introduction of social security. This point, already discussed in Imrohoroglu et al. (1999), explains why we, with a large IES of 5 find Pareto improvements via social security even for moderate degrees of risk aversion and return differentials between private assets and social security as observed in the data; in these examples the crowding-out effect is virtually absent and the welfare conclusions parallel those of the small open economy discussed previously.

Granting the reader freedom in choosing her or his own preferred preference parameters, we would interpret the findings documented in this section as suggesting that a Pareto improving introduction of social security is a possibility even from a quantitative point of view, but that for parameter values usually deemed reasonable in the macroeconomic literature such a Pareto improvement seems unlikely to occur. 


\section{Conclusion}

Can the introduction of an unfunded social security system provide a Pareto improvement by facilitating intergenerational risk sharing? In this paper we argue that, in the presence of incomplete markets, it potentially can do so in a quantitatively important way. However, in a realistically calibrated economy the intergenerational risk sharing role of unfunded social security is dominated in its importance by the adverse effect on capital accumulation arising from the introduction of such a system.

Future research could extend our work along several important dimensions. First, the current paper abstracts from several beneficial roles of an unfunded, redistributive social security system. In the presence of incomplete financial markets social security provides a partial substitute for missing insurance markets against idiosyncratic labor income and lifetime uncertainty. On the other hand the distortive effects of payroll taxes on the labor supply decision remain unmodeled as well. We abstract from these features to more clearly isolate the potential magnitude of the beneficial intergenerational risk sharing role of social security. A complete assessment of its relative quantitative importance, compared to the intragenerational risk sharing and distortion effects would require incorporating these effects explicitly, however. Whereas elastic labor supply would add limited complexity to the numerical algorithm by adding a control variable, allowing for uninsurable idiosyncratic uncertainty would generate intragenerational heterogeneity, a nontrivial wealth distribution within generations and thus induce the same curse of dimensionality that occurs when expanding the number of generations in the model.

Second, in this paper we are setting a very demanding bar that social security has to pass in order to be judged as welfare improving and therefore implementable. Employing the Pareto criterion our normative analysis is silent about the political conflict surrounding the adoption or reform of social security. Extensions of the work of Cooley and Soares (1997) and Boldrin and Rustichini (2000) to our environment with aggregate uncertainty are needed to address the question why, though not mutually beneficial, the US social security system was introduced when it was introduced and who one would expect the major supporters of this reform to be. 


\section{A Theoretical Appendix}

In this appendix we derive equation (4) explicitly. With $v(c)=\ln (c)(3)$ becomes

$$
\begin{aligned}
U^{\prime}(\tau & =0)=E\left\{\frac{G-R}{(1-0) R+0 * G}\right\}>0 \text { if and only if } \\
E\left\{\frac{G}{R}\right\} & >1
\end{aligned}
$$

We note that

$$
E\left(\frac{G}{R}\right)=E\left(e^{\ln (G)-\ln (R)}\right)=E\left(e^{\ln (Z)}\right)
$$

where $\ln (Z):=\ln (G)-\ln (R)$, so that $Z=\frac{G}{R}$. Since $(\ln (G), \ln (R))$ are jointly normal, both $\ln (G)$ and $\ln (R)$ are normal random variables, and thus $\ln (Z)$ is normal with mean $\mu_{\ln Z}=\mu_{\ln G}-\ln \ln R$ and variance $\sigma_{\ln Z}^{2}=$ $\sigma_{\ln G}^{2}+\sigma_{\ln R}^{2}-2 \sigma_{\ln G, \ln R}$. Since $Z$ is lognormal we have

$$
\begin{aligned}
E\left(\frac{G}{R}\right) & =E(Z)=e^{\mu_{\ln Z}+\frac{1}{2} \sigma_{\ln Z}^{2}} \\
& =e^{\mu_{\ln G}+\frac{1}{2} \sigma_{\ln G}^{2}} \cdot e^{-\left(\mu_{\ln R}+\frac{1}{2} \sigma_{\ln R}^{2}\right)} \cdot e^{\sigma_{\ln R}^{2}} \cdot e^{-\sigma_{\ln G, \ln R}}
\end{aligned}
$$

Since $G$ and $R$ are log-normal we have

$$
\begin{aligned}
& E(G)=e^{\mu_{\ln G}+\frac{1}{2} \sigma_{\ln G}^{2}} \text { and } E(R)=e^{\mu_{\ln R}+\frac{1}{2} \sigma_{\ln R}^{2}} \\
& \operatorname{Var}(R)=e^{2 \mu_{\ln R}+\sigma_{\ln R}^{2}} \cdot\left(e^{\sigma_{\ln R}^{2}}-1\right) \\
& =E(R)^{2} \cdot\left(e^{\sigma_{\ln R}^{2}}-1\right)
\end{aligned}
$$

We thus obtain

$$
\begin{aligned}
e^{\mu_{\ln G}+\frac{1}{2} \sigma_{\ln G}^{2}} & =E(G) \\
e^{-\left(\mu_{\ln R}+\frac{1}{2} \sigma_{\ln R}^{2}\right)} & =\frac{1}{E(R)} \\
e^{\sigma_{\ln R}^{2}} & =\frac{\operatorname{Var}(R)+E(R)^{2}}{E(R)^{2}}
\end{aligned}
$$

Finally we want to obtain an expression for $e^{-\sigma_{\ln G, \ln R}}$. But

$$
\begin{aligned}
\operatorname{Cov}(G, R) & =E(G R)-E(G) E(R)=E\left(e^{\ln (G)+\ln (R)}\right)-E(G) E(R) \\
& =e^{\mu_{\ln G}-\mu_{\ln R}+\frac{1}{2} \sigma_{\ln G}^{2}+\frac{1}{2} \sigma_{\ln R}^{2}+\sigma_{\ln G, \ln R}-E(G) E(R)} \\
& =E(G) E(R)\left(e^{\sigma_{\ln G, \ln R}}-1\right)
\end{aligned}
$$


and thus

$$
\begin{aligned}
e^{\sigma_{\ln G, \ln R}} & =\frac{\operatorname{Cov}(G, R)+E(G) E(R)}{E(G) E(R)} \\
e^{-\sigma_{\ln G, \ln R}} & =\frac{E(G) E(R)}{\operatorname{Cov}(G, R)+E(G) E(R)}
\end{aligned}
$$

Plugging in (27) - (31) into (25) yields

$$
\begin{aligned}
E\left(\frac{G}{R}\right) & =\frac{E(G)}{E(R)} \cdot \frac{\frac{\operatorname{Var}(R)+E(R)^{2}}{E(R)^{2}}}{\frac{\operatorname{Cov}(G, R)+E(G) E(R)}{E(G) E(R)}} \\
& =\frac{E(G)}{E(R)} \cdot \frac{\left[c v(R)^{2}+1\right]}{\left[\rho_{G, R} \cdot c v(G) \cdot c v(R)+1\right]}
\end{aligned}
$$

as in the main text.

\section{B Data Appendix}

We use data for 1929-2001, since reliable wage and stock market data are available only for this period. Our annual data on dividends and stock market prices, in order to compute returns on the S\&P 500 are taken from Shiller (1989) and the updates available on his web site. For annual wages we use total compensation of employees from the NIPA, divided by the total number of full-time and (full-time-equivalent) part-time employees. All variables are deflated by the deflator for total consumption expenditures from the NIPA. We remove a constant growth rate of 1.7 per annum from the wage data; the statistics referring to the wage data pertain to the so detrended data. Where applicable, we aggregate yearly data into 12 sixyear intervals to obtain data of frequency comparable to that of our models. 


\section{References}

[1] Aaron, H., A. Blinder, A. Munnell and P. Orzag (2000), "Governor Bush's Individual Account Proposal," mimeo, Brookings Institution.

[2] Abel, A., G. Mankiw, L. Summers and R. Zeckhauser (1989), "Assessing Dynamic Efficiency: Theory and Evidence," Review of Economic Studies, 56, 1-20.

[3] Attanasio, O. and G. Weber (1995), "Consumption Growth, the Interest Rate and Aggregation," Review of Economic Studies, 60, 631-649.

[4] Attanasio, O. and G. Weber (1995), "Is Consumption Growth Consistent with Intertemporal Optimization? Evidence for the Consumer Expenditure Survey," Journal of Political Economy, 103, 1121-1157.

[5] Barbie, M., M. Hagedorn and A. Kaul (2001), "Government Debt as Insurance against Macroeconomic Risk," Discussion paper 412, IZA Bonn.

[6] Bohn, H. (1998), "Risk Sharing in a Stochastic Overlapping Generations Economy," mimeo, University of California at Santa Barbara.

[7] Bohn, H. (1999), "Social Security and Demographic Uncertainty: The Risk Sharing Properties of Alternative Policies," NBER working paper 7030 .

[8] Boldrin, M and A. Rustichini (2000), "Political Equilibria with Social Security," Review of Economic Dynamics, 3, 41-78.

[9] Burtless, G. (2000), "Social Security Privatization and Financial Market Risk: Lessons from U.S. Financial History," mimeo, Brookings Institution.

[10] Cecchetti, S., P. Lam and N. Mark (1993), "The Equity Premium and the Risk-Free Rate: Matching the Moments," Journal of Monetary Economics, 31, 21-46.

[11] Cooley, T. and J. Soares (1997), "A Positive Theory of Social Security Based on Reputation," Journal of Political Economy, 107, 135-160.

[12] Demange, G. (2002), "On Optimality of Intergenerational Risk Sharing," Economic Theory, 20, 1-27. 
[13] Diamond, P. (1965), "National Debt in a Neoclassical Growth Model," American Economic Review, 55, 1127-1155.

[14] Diamond, P. (1977), "A Framework for Social Security Analysis," Journal of Public Economics, 8, 275-298.

[15] Epstein, L. and S. Zin (1989), "Substitution, Risk Aversion and the Temporal Behavior of Asset Returns: A Theoretical Framework," Econometrica, 57, 937-969.

[16] Gollier, C. (2001) The Economics of Risk and Time, MIT Press, Cambridge.

[17] Gouvenen, F. (2002), "Reconciling Conflicting Evidence on the Elasticity of Intertemporal Substitution: A Macroeconomic Perspective," mimeo, University of Rochester.

[18] Hansen, G. (1993), "The Cyclical and Secular Behavior of the Labor Input: Comparing Efficiency Units and Hours Worked," Journal of Applied Econometrics, 8, 71-80.

[19] Imrohoroglu, A., Imrohoroglu, S. and D. Joines (1999), "Social Security in an Overlapping Generations Economy with Land," Review of Economic Dynamics, 2, 638-665.

[20] Kandel, S. and R. Stambaugh (1991), "Asset Returns and Intertemporal Preferences," Journal of Monetary Economics, 27, 39-71.

[21] Kreps, D. and E. Porteus (1978), "Temporal Resolution of Uncertainty and Dynamic Choice Theory," Econometrica, 46, 185-200.

[22] Krueger, D. and F. Kubler (2002), "Computing OLG Models with Stochastic Production," mimeo, Stanford University.

[23] Merton, R. (1983), "On the Role of Social Security as a Means for Efficient Risk Sharing in an Economy Where Human Capital is Not Tradable," in Z. Bodie and J. Shoven (eds.) Financial Aspects of the United States Pension System, University of Chicago Press, Chicago.

[24] Samuelson, P. (1958), "An Exact Consumption Loan Model of Interest with or without the Social Contrivance of Money," Journal of Political Economy, 66, 467-482. 
[25] Shiller, R. (1989), Market Volatility, MIT Press, Cambridge.

[26] Shiller, R. (1999), "Social Security and Institutions for Intergenerational, Intragenerational and International Risk Sharing," CarnegieRochester Conference on Public Policy, 50, 165-204.

[27] Spear, S. (1988), "Existence and Local Uniqueness of Functional Rational Expectations Equilibria in Dynamic Economic Models," Journal of Economic Theory, 44, 124-155.

[28] Zilcha, I. (1990), "Dynamic Efficiency in Overlapping Generations Models with Stochastic Production," Journal of Economic Theory, 52, 364379 . 